\title{
Borderline Personality Disorder
}

National Cancer Institute

\section{Source}

National Cancer Institute. Borderline Personality Disorder. NCI Thesaurus. Code C92633.

A disorder characterized by an enduring pattern of unstable self-image and mood together with volatile interpersonal relationships, self-damag ing impulsivity, recurrent suicidal threats or gestures and/or self-mutilating behavior. 